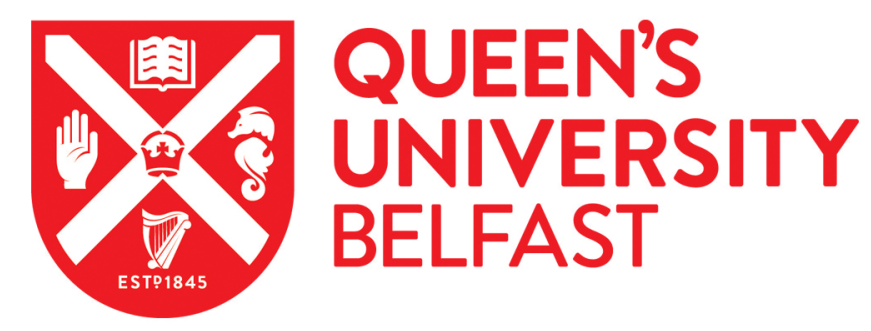

\title{
Missed opportunities! End of life decision making and discussions in implantable cardioverter defibrillator recipients
}

Miller, J., Chung, M., Etaee, F., Hammash, M., Thylen, I., Biddle, M., Elayi, S., Czarapata, M., McEvedy, S., Cameron, J., Haedtke, C., Ski, C., Thompson, D. R., \& Moser, D. (2019). Missed opportunities! End of life decision making and discussions in implantable cardioverter defibrillator recipients. Heart and Lung, 48(4), 313319. https://doi.org/10.1016/j.hrtlng.2019.04.006

Published in:

Heart and Lung

Document Version:

Peer reviewed version

Queen's University Belfast - Research Portal:

Link to publication record in Queen's University Belfast Research Portal

Publisher rights

(c) 2019 Elsevier Inc. All rights reserved.

This manuscript version is made available under the CC-BY-NC-ND 4.0 license http://creativecommons.org/licenses/by-nc-nd/4.0/,which permits distribution and reproduction for non-commercial purposes, provided the author and source are cited.

\section{General rights}

Copyright for the publications made accessible via the Queen's University Belfast Research Portal is retained by the author(s) and / or other copyright owners and it is a condition of accessing these publications that users recognise and abide by the legal requirements associated with these rights.

Take down policy

The Research Portal is Queen's institutional repository that provides access to Queen's research output. Every effort has been made to ensure that content in the Research Portal does not infringe any person's rights, or applicable UK laws. If you discover content in the Research Portal that you believe breaches copyright or violates any law, please contact openaccess@qub.ac.uk. 


\title{
Abstract:
}

Background: Recent guidelines highlight the need for clinician-patient discussions regarding end-of-life (EOL) choices prior to implantable cardioverter defibrillator (ICD) implantation. Health literacy could affect the quality and quantity of such discussions.

Objective: Our objective was to determine the association of health literacy with experiences, attitudes, and knowledge of the ICD at EOL.

Methods: In this cross-sectional study, we used validated instruments to measure health literacy and patient experiences, attitudes, and knowledge of the ICD at EOL.

Results: Of the 240 ICD recipients, $76 \%$ of participants reported never having discussed the implications of a future withdrawal of defibrillation therapy with their healthcare provider. Increased odds of choosing to maintain defibrillation therapy were associated with female gender and lower ICD knowledge.

Conclusions: From patients' perspectives, EOL discussions with providers were minimal. Most patients hold misperceptions about ICD function that could interfere with optimal EOL care, particularly for those with inadequate health literacy.

Keywords: Implantable Cardioverter Defibrillator; End of Life, End-of-Life Issues in Implantable Cardioverter Defibrillator Patients Questionnaire; Hospital Anxiety and Depression Scale; Newest Vital Sign.

\author{
Abbreviations: \\ EOL: End of Life \\ Questionnaire \\ HADS: Hospital Anxiety and Depression Scale \\ ICD: Implantable Cardioverter Defibrillator \\ NVS: Newest Vital Sign
}

EOL-ICDQ: End-of-Life Issues in Implantable Cardioverter Defibrillator Patients 


\section{Introduction}

Implantable cardioverter defibrillators (ICDs) are the main therapy for primary and secondary prevention of sudden cardiac arrest. ${ }^{1,2}$ Approximately 737,840 new ICD implantations and 264,824 generator replacements are performed annually worldwide. ${ }^{3,4}$ Many of these devices are implanted in individuals with heart failure (HF) because sudden dysrhythmic death is a common cause of death in HF. ${ }^{2}$ As sudden cardiac death becomes less likely in HF patients with an ICD, most will die from progression of HF or from another terminal illness. Even among patients with an ICD and without HF, death from a non-cardiac terminal illness is likely. Mean life expectancy following ICD implantation is 2.5 years. $^{2}$ Approximately $33 \%$ of ICD recipients receive a shock while actively dying, which may lead to unnecessary prolongation and poor quality of the death experience. ${ }^{5}$

Recent guidelines for management of patients with ventricular dysrhythmias and prevention of sudden cardiac death by the American College of Cardiology/American Heart Association/Heart Rhythm Society (ACC/AHA/HRS) recommend that clinicians begin discussions at time of implantation with ICD recipients regarding end-of-life (EOL) choices. These discussions should include generator replacement and withdrawal of defibrillation therapy in the context of terminal illness and be based on patient preferences and values at the time. ${ }^{6}$ Such discussions are necessary for fully informed consent, greater patient, family and provider satisfaction with the care process, and fully informed decisionmaking with regard to EOL choices.

The decision-making process is strongly affected by health literacy levels. Health literacy is defined as the degree to which individuals have the capacity to obtain, process, 
and understand basic health information and services needed to make appropriate health decisions. ${ }^{7}$ Inadequate health literacy impairs one's ability to assess risk versus benefit information, participate in plans of treatment, fully engage in self-care, and communicate choices. ${ }^{8}$ Inadequate health literacy affects the ability to fully understand EOL care options. The main goal of EOL decision making is to explore an individual's values and preferences for care based upon a full understanding of all of the options. Ensuring that individuals and families have a complete understanding of EOL care options may improve the quality of the death experience allowing for death with dignity that is congruent with beliefs and values system. Therefore, the overall purpose of this study was to determine the association of health literacy with experiences, attitudes, and knowledge of the ICD at EOL by ICD recipients.

The specific aims of this study were to:

1. identify experiences and attitudes about discussions held with healthcare providers regarding EOL choices (generator replacement and maintenance of defibrillation therapy) among ICD recipients

2. determine the level of knowledge regarding ICD function at EOL among ICD recipients and compare knowledge by inadequate and adequate health literacy.

3. determine the association of health literacy with experiences, attitudes and knowledge regarding EOL choices among ICD recipients

\section{Methods}


This cross-sectional study was approved by institutional review boards at two central Kentucky universities in the United States and a hospital ethics board in Melbourne, Australia.

\section{Participants}

Participants were recruited from general cardiology, electrophysiology, and heart failure clinics of tertiary hospitals in central Kentucky, United States, and Melbourne Australia. Eligibility criteria included: ICD insertion $>12$ months, ability to read and speak English, no severe cognitive impairment that precluded providing informed consent, no institutionalization (i.e., nursing home placement), no current ventricular assistive device placement or level one status on heart transplant list.

\section{Procedures}

Data were collected between 2015 and 2016. Research nurses screened medical records for eligibility before approaching individuals in the clinic setting. Additionally, potential participants were identified by healthcare providers practicing in the relevant clinics. The participants gave informed consent and were provided with a signed copy of their consent form and a paper copy of the study questionnaire. Participants completed the survey online, in the clinic, or by mail based upon their preference. Those who had not completed or returned the questionnaire within two weeks were contacted by the research nurse either by phone or mailed reminder.

\section{Measures}

Study questionnaires consisted of a sociodemographic survey; the Experiences, Attitudes, and Knowledge of End-of-Life Issues in Implantable Cardioverter Defibrillator 
Patients Questionnaire (EOL-ICDQ), and the Newest Vital Sign (NVS). We measured anxiety and depression as covariates using the Hospital Anxiety and Depression Scale (HADS). The socio-demographic questionnaire included questions of age, gender, ethnicity, and history of shock and generator replacement.

\section{ICD Experiences, Attitudes, and Knowledge}

The EOL-ICDQ is a 39-item instrument developed in Sweden to measure experiences, attitudes, and knowledge of EOL issues in ICD recipients. The instrument has known validity and reliability in ICD recipients. ${ }^{9}$ Two items from the experiences subscale were used in the analysis of discussions with healthcare providers 'Have you discussed what a change of battery involves with your ICD doctor or nurse' and 'Have you discussed what turning off the shocks in your device involves with your ICD doctor or nurse?' Participants had the option of choosing yes/no/or decline to answer.

Attitudes about the ICD at EOL were measured by answers yes/no/cannot take a stand to the following question scenarios 'I want to have the battery in my ICD replaced: even if I am seriously ill and suffering from another disease' and 'I want to keep the shocks in my ICD: even if dying of cancer or another serious disease'.

Knowledge of the ICD was measured using the 11-item knowledge subscale of the EOL-ICDQ. True/false/don't know answers are chosen by the respondent to statements (e.g., to turn off the ICD shocks is the same as active euthanasia; an ICD always delivers shocks at the end of life). The correct answers are summed for a total value of $0-11$, with higher scores indicating a higher level of ICD knowledge. The Cronbach's alpha for the ICD knowledge subscale in this study was 0.741 . 


\section{Health Literacy}

Health literacy was measured in this study using the Newest Vital Sign (NVS). The NVS is a 6-item questionnaire used to assess the ability to read and apply information from a nutrition label that can be completed quickly in the clinical setting. ${ }^{10}$ Scores range from 0 to 6 and represent the number of questions answered correctly, with higher scores indicating higher levels of health literacy. Scores of 4 or more correct answers indicate adequate health literacy. ${ }^{10}$ This instrument has been found to be valid and reliable in multiple populations. ${ }^{11}$ The Cronbach's alpha for this instrument in our study was 0.991 .

\section{Anxiety and Depressive Symptoms}

The Hospital Anxiety and Depression Scale (HADS) is a 14-item instrument that includes two subscales that measure anxiety and depression ( 7 items each). Scores on each subscale range from 0 to 21 where higher scores reflect higher levels of anxiety or depressive symptoms. The reliability and validity of the HADS have been demonstrated in multiple populations. ${ }^{12}$ The Cronbach's alpha for the overall scale in our study was 0.844 with the anxiety and depressive subscale Cronbach's alpha 0.787 and 0.739 respectively.

\section{Analysis}

All analyses were conducted using SPSS, version 22. Characteristics were compared between those with adequate and inadequate health literacy using $t$-tests and $x^{2}$ tests.

ICD recipients' experiences and perspectives of conversations with healthcare providers regarding generator replacement and the maintenance of defibrillation therapy were examined by asking if they had spoken with their healthcare provider about these 
specific topics. The numbers and percentages of those who answered yes regarding these discussions with their healthcare provider were further explored by comparing the reports of discussions within health literacy categories using $\mathrm{x}^{2}$ tests.

Knowledge of the ICD at EOL was examined by the percentage of incorrect answers to the questions posed on the ICD knowledge portion of the EOL-ICDQ. ${ }^{9}$ The number and percentage of incorrect answers were further explored by comparing incorrect answers based on health literacy categories (inadequate vs. adequate) using $\mathrm{x}^{2}$ tests.

Multinomial regression was used to determine whether health literacy was a predictor of attitudes toward generator replacement and maintenance of defibrillation therapy (yes/no/can't take a stand) in the context of terminal illness while controlling for sociodemographic variables (gender, age, ethnicity), psychosocial variables (anxiety and depression), and ICD related variables (shock experience, generator replacement, and ICD knowledge). Assumptions for multi-nominal regression were tested, and none were violated.

\section{Results}

\section{Sample}

A total of 274 individuals participated in the study. Two hundred forty of the participants for whom data for all of the variables of interest was complete were included in this analysis (Table 1). There were no significant differences in sociodemographic or clinical variables between those who were included in the analysis and those who were not. 
The mean age of the overall sample was $62 \pm 14$ years, $28 \%$ of participants were female and $16.7 \%$ self-identified as a minority. Thirty-five percent had a history of a previous shock, and $30.4 \%$ had experienced generator replacement.

The mean health literacy level of the participants was $3.07 \pm 2.21$, as measured on by the Newest Vital Sign (range 0-6, with scores greater than or equal to 4 indicating adequate health literacy. There were differences in participant characteristics between individuals with inadequate and adequate levels of health literacy (Table 1). Those with inadequate levels of health literacy were older $(64 \pm 13$ vs. $59 \pm 14, p$ value .002$)$, more often minorities $(23.3 \%$ vs. $10.0 \%, p$ value .011$)$, and were less likely to have had the ICD generator replaced $(23.8 \%$ vs. $38.2 \%)$.

\section{Experiences- Discussions with Healthcare Providers}

Sixty-three percent of participants reported discussions with their healthcare provider regarding generator replacement. Individuals within the inadequate health literacy category reported more often that discussions with their health care provider regarding a generator change had not taken place (45.4\% vs. $28.2 \%$, p-value .006$)$.

Twenty-four percent of participants reported discussions with their healthcare provider about the withdrawal of defibrillation therapy. Individuals within the inadequate health literacy category reported more often that discussions with their health care provider regarding a defibrillation therapy withdrawal had not taken place $(81.5 \%$ vs. $70 \%$, p-value $.036)$.

\section{ICD Knowledge}


Misconceptions regarding the ICD were apparent in the overall population. The percentage of incorrect answers on the ICD knowledge portion of the EOL-ICDQ ranged from $20-62 \%$ per question (Table 2). The overall ICD knowledge score in the total sample was $5.6 \pm 3$ (from a total possible of 11 ). The total score was higher in the adequate health literacy group compared to the inadequate health literacy group $(6.4 \pm 3$ vs. $5.0 \pm 2.8, p<$ $.001)$.

Nearly $40 \%$ of individuals believed that withdrawal of defibrillation therapy was the same as active euthanasia and that the therapy could be turned off without their knowledge. Sixty-two percent of participants believed that the ICD always delivers a shock at the EOL and that if defibrillation therapy is withdrawn that the device no longer functions as a pacemaker. Twenty percent of those asked believed that once defibrillation therapy was withdrawn, the heart would cease to beat. Thirty-eight percent of people believed that the device must be removed surgically to withdrawal defibrillation therapy and $37 \%$ believe that once the defibrillation therapy is withdrawn it cannot be resumed.

There were notable differences in ICD knowledge based on health literacy category. Those with inadequate levels of health literacy were more likely to answer ICD knowledge questions incorrectly. Those with inadequate health literacy compared to those with adequate health literacy incorrectly believed that 1) the ICD must be removed to disable defibrillation therapy $(46.2 \%$ vs. $28.4 \%$. p-value, .005$), 2)$ once disabled ICD shocks could not be enabled again (43.1\% vs. $29.4 \%$, p-value, .029), 3) turning off defibrillation therapy was the same as active euthanasia (46.9 \% vs. $26.6 \%$, p-value, .001$)$, 4) ICD shocks could not be temporarily disabled temporarily by magnet $(62.3 \%$ vs. $45.0 \%$, p-value, .007), 5) the device's function would worsen as the battery began to deplete 
$(69.2 \%$ vs. $43.1 \%$, p-value, $<.001)$, and 6$)$ when the ICD shocks were turned off that the pacemaker function ceased (71.3\% vs. $49.5 \%$, p-value, .001).

\section{Predictors of Attitudes about the ICD at EOL}

Multinomial logistic regression was performed to determine predictors of attitudes regarding EOL choices. Models were developed for both the generator replacement and defibrillation maintenance scenarios (Tables $3 \& 4$ ). Both models contained nine variables (gender, age, ethnicity, shock experience, generator replacement, ICD knowledge, and health literacy). Results are presented as odds for answering yes or cannot take a stand by scenario question. These responses represent choices (generator replacement and/or maintaining defibrillation therapy in the context of terminal illness) that put the ICD recipient at risk for unnecessary shocks at the EOL. The models are presented below.

\section{Generator Replacement}

Significant predictors of increased odds of answering yes to choosing to have generator replacement in the context of terminal illness scenario were symptoms of anxiety, health literacy, and a positive history of shock (Table 3). For every one-unit increase in anxiety or health literacy the odds of choosing generator replacement increased by $14 \%$ ( $p$ $=.017)$ and $19 \%(p=.046)$ respectively. For those who had a history of previous shock the odds of choosing to replace the generator were increased 2.156 times $(p=.045)$.

Predictors of decreased odds of answering yes to generator replacement in the context of terminal illness scenario were self-reported minority status (non-Caucasian), symptoms of depression, and increased ICD knowledge (Table 3). The odds of minorities choosing to replace the generator were $80.3 \%(p=.018)$ less than their Caucasian 
counterparts. For every one-unit increase in depressive symptoms and ICD knowledge the odds of choosing to replace the generator were decreased by $15.8 \%(p=.001)$ and $13.8 \%$ $(p=.046)$

The sole predictor of increased odds of indecisiveness (answering cannot take a stand) to generator replacement in the context of terminal illness scenario was health literacy (Table 3). For every one-unit increase in health literacy the odds of indecisiveness were increased by $19.4 \%(p=.046)$. The sole predictor of decreased odds of indecisiveness (answering cannot take a stand) to generator replacement in the context of terminal illness scenario was ICD knowledge (Table 3). For every one-unit increase in ICD knowledge the odds of indecisiveness decreased by $20.4 \%(p=.009)$.

\section{Defibrillation Therapy Maintenance}

The sole predictor of increased odds of answering yes to the maintenance of defibrillation therapy in the context of terminal illness scenario was female gender (Table 4). The odds of women choosing to maintain defibrillation therapy were 2.288 times higher $(p=.027)$ than that of their male counterparts. The sole predictor of decreased odds of choosing to maintenance of defibrillation therapy in the context of terminal illness scenario was ICD knowledge (Table 4). For every one-unit increase in ICD knowledge the odds of choosing to maintain defibrillation therapy were decreased by $11.4 \%(p=.038)$. None of the variables presented in the model were predictors of increased/decreased odds of indecisiveness (answering cannot take a stand) to the maintenance of defibrillation therapy in the context of terminal illness scenario (Table 4).

\section{Discussion}




\section{Experiences of Discussions with Healthcare Providers}

According to the perspective of the ICD recipient, adherence to the guidelines regarding EOL discussions was minimal as most patients report that these discussions with their healthcare provider have not taken place. The healthcare provider's role in the decision-making process is to present the facts, risks, and benefits in a concise and understandable manner.

Exploration of the roles of providers and recipients in these discussions has identified barriers to full discussion of the impact of the ICD at the EOL. Raphael et al. ${ }^{13}$ presented the results of a study that identified the following barriers to the discussion of ICD deactivation; the recipients' understanding of the device and the healthcare providers' willingness to discuss the topic.

ICD recipients often overestimate the benefit of the ICD. ${ }^{14}$ Goldstein et al. ${ }^{15}$ reported that in a focus group of 15 ICD recipients, none of the participants reported having discussions with healthcare providers regarding the withdrawal of defibrillation therapy and all of the participants believed the ICD was exclusively beneficial. Many recipients feel the healthcare provider will bring up the topic of EOL choices when the time arises. If the healthcare provider does not initiate the discussion of EOL choices due to discomfort with the topic the patient may infer that it is not an important. ${ }^{16}$

\section{Predictors of Attitudes Related to EOL}

Health literacy was a predictor of increased odds of choosing to replace the generator in the context of terminal illness but was not a significant factor in relation to choices regarding defibrillation therapy withdrawal and was not a predictor of decisiveness 
regarding EOL choices in either model. This finding was unexpected and may be related to significantly low levels of both health literacy and ICD knowledge in the study participants. Additionally, health literacy as measured in this study increased the risk of indecisiveness regarding generator replacement. Future studies should utilize a health literacy tool specifically related to EOL and/or ICD recipients.

ICD knowledge was a predictor of decreased odds of choosing to replace the generator, maintaining defibrillation therapy, and indecisiveness regarding generator replacement in the context of terminal illness. Improving ICD knowledge may have a meaningful impact on risk reduction and interventions to improve ICD knowledge may help to decrease unnecessary invasive procedures for generator replacement and shocks during the active dying phase, thus improving both the quality of life and the quality of the death experience for ICD recipients. ${ }^{14-16}$ In this study the mean ICD knowledge score was 5.57 out of 11 , equating to scores of approximately $50 \%$. These low scores in combination with low levels of health literacy are detrimental to a full understanding of ICD function throughout the trajectory of illness and particularly as the device relates to EOL decisionmaking. Health literacy affects the application of ICD knowledge in the decision-making process therefore further exploration of health literacy as a mediator or moderator of ICD knowledge and EOL decision-making is warranted to better understand the relationship of these variables.

Additionally, we found that women were at risk for disparate EOL experiences regarding ICDs. Female gender was a predictor of choosing to maintain defibrillation therapy in the context of terminal illness. This leaves women at increased risk of shocks in the active dying phase. The overall ICD experience of women is different from that of a 
man. ${ }^{17}$ Future studies should investigate the disparities in the overall ICD experience and interventions should be developed with the needs of women in mind.

Interestingly, we found that minorities were at the same or decreased odds of choosing to replace the generator and maintain defibrillation therapy in the context of terminal illness. This conflicts with other studies in the literature which indicate that minorities prefer more aggressive treatments at EOL. ${ }^{18,19}$ Approximately $17 \%$ of the participants in this study self-identified as minorities. Small numbers of some groups required a combination of multiple different racial and ethnic groups which could have made it difficult to parse out this important concept as it relates to EOL. There are many strongly held cultural beliefs regarding death and the dying process. Future studies should specifically target a sufficient number of minority participants for a comparison of these groups.

We found that psychological comorbidities also affect the EOL decision-making process of ICD recipients by affecting the odds of choosing to replace the generator in the context of terminal illness. Anxiety increased these odds and depression lowered them. Those who are anxious may feel the need to attempt to control their health outcomes by undergoing procedures that are not completely necessary and those who are depressed may choose not to do so due to the state induced by their psychological distress.

Anxiety may cause an individual to feel frozen, thereby rendering them unable to make a decision or to make decisions based upon their psychological state rather than their values and beliefs. Individuals experiencing depression often exhibit negative thinking which may cloud the decision-making process. ${ }^{20}$ Anxiety and depression have been shown 
to impact the quality of life in ICD recipients, ${ }^{21}$ and the results of this study indicate that these comorbid conditions can impact the quality of the death experience as well. In order for ICD recipients to have the best opportunity to make decisions regarding EOL that are truly in line with their personal values and beliefs is to make certain that they are doing so in the clearest state of mind possible. ICD recipients should be screened for anxiety and depression and be referred to psychiatric providers for appropriate treatment.

Study participants who had a history of ICD shock were 2.156 times more likely to choose to replace the generator in the context of terminal illness. EOL decision making is a dynamic process and may change based on ICD recipient experiences. Those who feel that their device prevented them from dying once may be more likely to decide to maintain defibrillation therapy. Oftentimes those who have had a shock feel that the device will save them from death of any cause. ${ }^{22,23}$ "It saved my life, and I don't want to live without it" is a common refrain of ICD recipients who have experienced a shock. ${ }^{22}$ This overestimation of the benefits of the device may lead to impaired decision making.

The scenarios regarding EOL choices in this study were hypothetical, and it is important to understand that as health conditions change, so may an individual's perception of what constitutes quality of life. Decisions regarding EOL care may change over time based on the severity of illness and the progression of disease in an individual. Living a life of quality can take on different meaning as death looms closer. ${ }^{24}$

\section{ICD Knowledge}

We found that ICD recipients held major misconceptions regarding the function of the ICD at EOL and that individuals with inadequate health literacy were more likely to 
hold these misconceptions. These misconceptions may affect the decision-making process related to EOL choices, ultimately interfering with optimal care. Educational interventions should focus on explaining the function of the ICD and how it affects the dying process. An understanding of these facts is lacking in a significant number of ICD recipients and a full comprehension of the device function may affect EOL choices. When provided with full details of the function of the ICD at EOL, a majority of people choose to forego generator replacement and withdraw defibrillation therapy in the context of terminal illness. Dodson et al. ${ }^{12}$ found that when provided information regarding the function of the ICD $71 \%$ of patients would choose to withdraw defibrillation therapy at EOL.

\section{Strengths and Limitations}

Strengths of this study include a large sample size and inclusion of similarly situated ICD recipients in Australia. The system of medical care differs in Australia but the standard of care for treatment of ICD recipients is similar. The inclusion of this population highlights the global need for ICD specific advanced directives.

Limitations include the cross-sectional nature of this study particularly in light of the dynamic nature of EOL choices. EOL choices in this study were presented as hypothetical scenarios. Actual decision making related to the ICD at the EOL may differ from a hypothetical choice during a relatively stable time in the trajectory of device treatment.

\section{Clinical Implications}

Advanced care planning for ICD recipients is lacking in current practice. There is a need for thorough communication regarding EOL choices in ICD recipients prior to 
implant and throughout the trajectory of illness. The EOL-ICDQ could be used in the clinical setting to ease these discussions. Further research should focus on educational and counseling interventions to improve understanding of the function of the ICD and its impact on the quality of life during ICD therapy, as well as advance directives specific to the ICD regarding generator replacement and the withdrawal or maintenance of defibrillation therapy in the context of terminal illness. Health literacy should be assessed as a routine part of patient education and counseling. The NVS instrument is appropriate and feasible to use in the clinical setting. Additionally, these interventions should include family members and informal caregivers as often EOL decision-making is a family and value driven process.

Additionally, inclusion of a palliative medicine consult could be very beneficial for patients and family. The trajectory of heart failure is difficult to predict and the mean survival time following implantation of ICD is only 2.5 years. ${ }^{2}$ The timeframe for providing ICD recipients with the knowledge necessary to make EOL decisions is very short. A palliative medicine consult at the time of ICD implantation is controversial.

Advanced directives improve the quality of the death experience by facilitating death with dignity for the individual and improving psychological outcomes for the bereaved family. ${ }^{25}$ Only eight percent of ICD recipients have advanced directives. Of those ICD recipients who have written formal advanced directives, only $1-2 \%$ have wording that specifically addresses deactivation of the ICD in the context of terminal illness. ${ }^{25}$ Future research should focus on programs to improve delineation of values driven EOL decisionmaking for ICD recipients. 


\section{Conclusion}

Social determinants of health (gender, race, and health literacy), psychosocial comorbidities, and ICD knowledge affect the EOL decision-making process in ICD recipients. These issues should be included in planning for further research and interventions in this population to improve understanding of the function of ICDs and to reduce disparities in the quality of life and the death experience is this population.

\section{Declarations of interest: none}

Funding: This research did not receive any specific grant from funding agencies in the public, commercial, or not-for-profit sectors. 


\section{References}

1. Zipes DP, Wyse DG, Friedman PL, et al. A comparison of anti-arrythmic drug therapy with implantable defibrillators in patients resuscitated from near-fatal ventricular arrythmias. New England Journal of Medicine. 1997;337:1576-1584.

2. Benjamin, EJ, Virani, SS, Callaway, CW, et al. Heart disease and stroke statistics--2018 update: a report from the American Heart Association. Circulation. 2018;137:e67-e492.

3. Kremers MS, Hammill SC, Berul CI, et al. The National ICD Registry Report: version 2.1 including leads and pediatrics for years 2010 and 2011. Heart Rhythm. 2013 Apr 1;10(4):e59-65. 4. Mond HG and Proclemer A. The 11th world survey of cardiac pacing and implantable cardioverter-defibrillators: calendar year 2009--a World Society of Arrhythmia's project. Pacing and Clinical Electrophysiology : PACE. 2011;34:1013-27.

5. Westerdahl AK, Sutton R and Frykman V. Defibrillator patients should not be denied a peaceful death. International Journal of Cardiology. 2015;182:440-6.

6. Al-Khatib, SM, Stevenson, WG, Ackerman, MJ, et al. 2017 AHA/ACC/HRS guideline for management of patients with ventricular arrhythmias and the prevention of sudden cardiac death: A report of the American College of Cardiology /American Heart Association task force on clinical practice guidelines for the Heart Rhythm Society. Heart Rhythm. 2018;15:e73-189.

7. Ratzan, S. C., \& Parker, R. M. (2000). Introduction. In C. R. Selden, M. Zorn, S. C. Ratzan, \& R. M. Parker. (Eds.), National library of medicine current bibliographies in medicine: Health literacy. NLM Pub. No. CBM 2000-1. Bethesda, MD: National Institutes of Health, U.S. Department of Health and Human Services.

8. Paasche-Orlow MK and Wolf MS. The Causal Pathways Linking Health Literacy to Health Outcomes. American Journal of Health Behavior. 2007;31:S19-S26.

9. Thylen I, Wenemark M, Fluur C, et al. Development and evaluation of the EOL-ICDQ as a measure of experiences, attitudes, and knowledge in end of life in patients living with an 
implantable cardioverter defibrillator. European Journal of Cardiovascular Nursing. 2013;13:142151.

10. Weiss BD, Mays MZ, Martz W, et al. Quick assessment of literacy in primary care: the newest vital sign. Annals of Family Medicine. 2005;3:514-22.

11. Heinrich C. Health literacy: The sixth vital sign. Journal of the American Academy of Nurse Practitioners. 2012 Apr;24(4):218-23.

12. Zigmond AS and Snaith RP. The hospital anxiety and depression scale. Acta Psychiatr Scand. $1983 ; 67: 361-370$.

13. Raphael CE, Koa-Wing M, Stain N, et al. Implantable cardioverter-defibrillator recipient attitudes towards device deactivation: how much do patients want to know? Pacing and Clinical Electrophysiology.. 2011;34:1628-33.

14. Goldstein NE, Mehta D, Siddiqui S, et al. "That's like an act of suicide" patients' attitudes toward deactivation of implantable defibrillators. Journal of General Internal Medicine. 2008;23 Suppl 1:7-12.

15. Goldstein NE, Mehta D, Teitelbaum E, Bradley EH and Morrison RS. "It's like crossing a bridge" complexities preventing physicians from discussing deactivation of implantable defibrillators at the end of life. Journal of General Internal Medicine. 2008;23 Suppl 1:2-6.

16. Thylén I, Moser DK, Chung ML,et al. Are ICD recipients able to foresee if they want to withdraw therapy or deactivate defibrillator shocks? International Journal of Cardiology Heart \& Vessels. 2013;1:22-31.

17. Lin, G, Meverden, RA, Hodge, DO, Uslan, DZ, Hayes, DL and Brady, PA. Age and gender trends in in implantable cardioverter utilization: A population based study. Journal of Interventional Cardiac Elsctrophysiology. 2016; 1:65-70.

18. Volandes AE, Paasche-Orlow M, Gillick MR, et al. Health literacy not race predicts endof-life care preferences. Journal of Palliative Medicine. 2008;11:754-62. 
19. Laguna J, Enguidanos S, Siciliano M and Coulourides-Kogan A. Racial/ethnic minority access to end-of-life care: a conceptual framework. Home Health Care Services Quarterly. 2012;31:60-83.

20. Dekker RL. Cognitive behavioral therapy for depression in patients with heart failure: a critical review. The Nursing Clinics of North America. 2008;43:155-70; viii.

21. Miller JL, Thylen I and Moser DK. Gender Disparities in Symptoms of Anxiety, Depression, and Quality of Life in Defibrillator Recipients. Pacing and Clinical Electrophysiology. 2016;39:149-59.

22. Fluur C, Bolse K, Stromberg A and Thylen I. Patients' experiences of the implantable cardioverter defibrillator (ICD); with a focus on battery replacement and end-of-life issues. Heart \& Lung :The Cournal of Critical Care. 2013;42:202-7.

23. Stromberg A, Fluur C, Miller J, et al. ICD recipients' understanding of ethical issues, ICD function, and practical consequences of withdrawing the ICD in the end of life. Pacing and Clinical Electrophysiology. 2014;37:834-842.

24. Allen LA, Stevenson LW, Grady KL, et al. Decision maing in advanced heart failure: A scientific statement from the American Heart Association. Circulation. 2012;125:1928-1952.

25. Tajouri, TH, Ottenberg, AL, Hayes, DL, \& Mueller, PS. The use of advanced directives among patients with implantable cardioverter defibrillators. Pacing and Clinical Electrophysiology. 2012;35;567-573. 


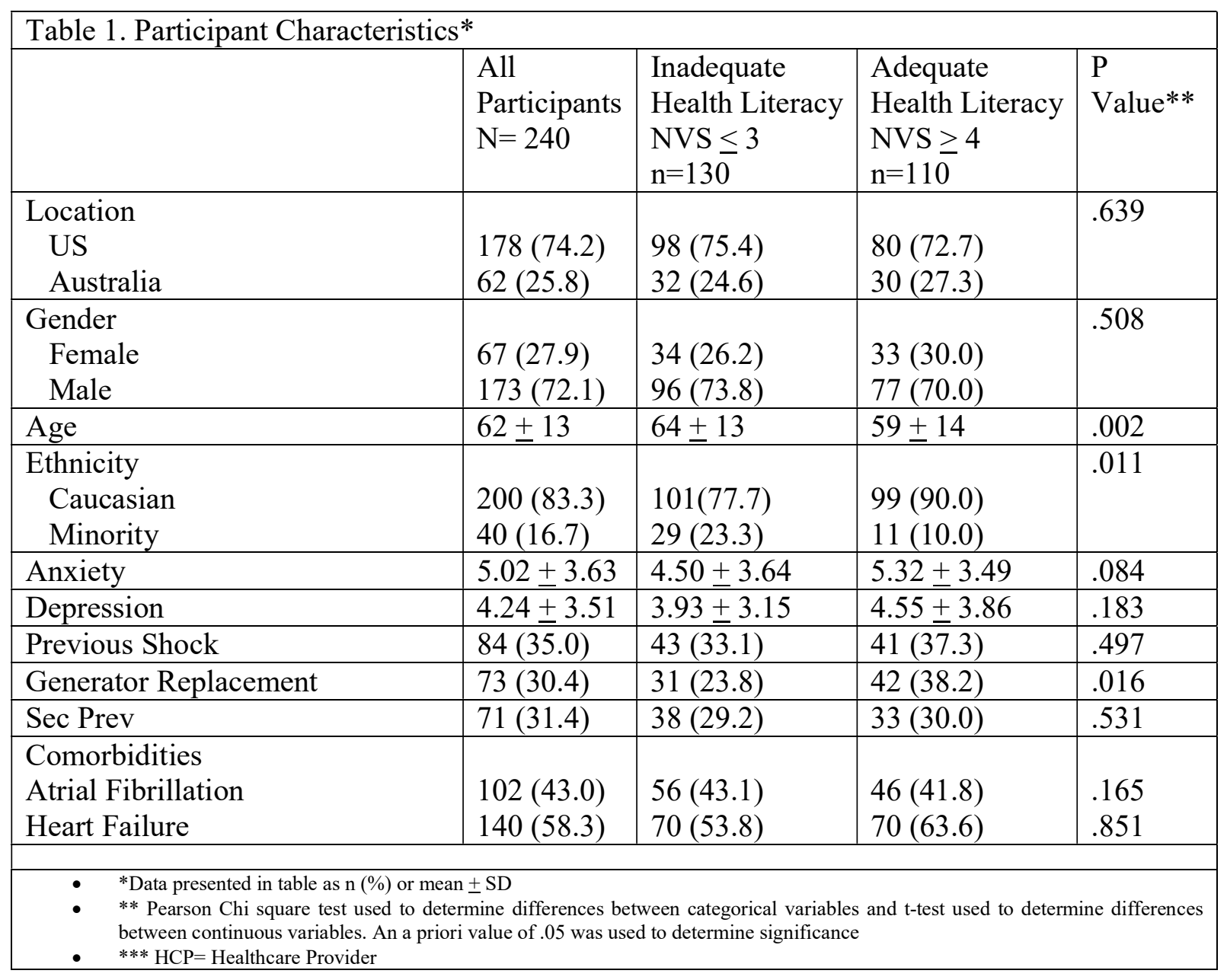


Table 2. Percentage of Participants Providing Incorrect Answers on ICD Knowledge Questionnaire by Health Literacy Category

\begin{tabular}{|c|c|c|c|c|}
\hline & $\begin{array}{l}\text { All } \\
\text { Participants } \\
\mathrm{N}=240\end{array}$ & $\begin{array}{l}\text { Inadequate } \\
\text { Health } \\
\text { Literacy } \quad \mathrm{n}= \\
130 \\
\mathrm{n}(\%)\end{array}$ & $\begin{array}{l}\text { Adequate } \\
\text { Health } \\
\text { Literacy } \mathrm{n}= \\
110 \\
\mathrm{n}(\%)\end{array}$ & $\begin{array}{l}\mathrm{P} \\
\text { Value }\end{array}$ \\
\hline $\begin{array}{l}\text { In order to turn off the } \\
\text { defibrillating shocks in an ICD, } \\
\text { the ICD must be removed by } \\
\text { surgery }\end{array}$ & $91(38.1)$ & $60(46.2)$ & $31(28.4)$ & .005 \\
\hline $\begin{array}{l}\text { When the ICDs defibrillating } \\
\text { shocks have been turned off, they } \\
\text { can't be turned on again }\end{array}$ & $88(36.8)$ & $56(43.1)$ & $32(29.4)$ & .029 \\
\hline $\begin{array}{l}\text { When an ICDs defibrillating } \\
\text { shocks are turned off, the heart } \\
\text { stops beating }\end{array}$ & $48(20.1)$ & $29(22.3)$ & $19(17.4)$ & .349 \\
\hline $\begin{array}{l}\text { An ICDs defibrillating shocks can } \\
\text { be turned off without my or my } \\
\text { relative's knowledge }\end{array}$ & 93 (38.9) & $49(37.7)$ & $44(40.4)$ & .673 \\
\hline $\begin{array}{l}\text { To turn off the defibrillating } \\
\text { shocks in an ICD is the same as } \\
\text { actively ending my life }\end{array}$ & $90(37.7)$ & $61(46.9)$ & $29(26.6)$ & .001 \\
\hline $\begin{array}{l}\text { In order to turn off the ICDs } \\
\text { defibrillating shocks, a temporary } \\
\text { deactivation can be done via a } \\
\text { magnet }\end{array}$ & $130(54.4)$ & $81(62.3)$ & $49(45.0)$ & .007 \\
\hline $\begin{array}{l}\text { In connection with the } \\
\text { defibrillating shock, the shock is } \\
\text { also transferred to those persons } \\
\text { having direct bodily contact }\end{array}$ & $129(54.0)$ & $71(54.6)$ & $58(53.2)$ & .828 \\
\hline $\begin{array}{l}\text { When an ICD's battery voltage is } \\
\text { beginning to wear, even the ICD's } \\
\text { functioning worsens }\end{array}$ & $137(57.3)$ & $90(69.2)$ & $47(43.1)$ & $<.001$ \\
\hline $\begin{array}{l}\text { An ICD always delivers } \\
\text { defibrillating shocks in connection } \\
\text { with end-of-life }\end{array}$ & $147(61.5)$ & $83(63.8)$ & $64(58.7)$ & .417 \\
\hline $\begin{array}{l}\text { In order to turn off the ICDs } \\
\text { defibrillating shocks a } \\
\text { reprogramming can be performed } \\
\text { by an external programmer }\end{array}$ & $72(30.1)$ & $46(35.4)$ & $26(23.9)$ & .053 \\
\hline $\begin{array}{l}\text { When the ICD's defibrillating } \\
\text { shocks are turned off, the } \\
\text { pacemaker function in the ICD is } \\
\text { also deactivated }\end{array}$ & $146(61.3)$ & $92(71.3)$ & $54(49.5)$ & .001 \\
\hline
\end{tabular}




\begin{tabular}{|l|l|l|l|l|l|}
\hline \multicolumn{5}{|l|}{$\begin{array}{l}\text { Table 3. Multinomial Regression for Predictors of Generator Replacement } \\
\text { Reference group: No to generator change in the context of terminal illness }\end{array}$} \\
\hline & \multicolumn{2}{|l|}{ Yes to generator change } & & \multicolumn{2}{l|}{ Indecisive } \\
\hline & $\begin{array}{l}\text { Odds Ratio } \\
(95 \% \text { CI })\end{array}$ & $\begin{array}{l}\text { Palue } \\
\text { Odds Ratio } \\
(95 \% \text { CI })\end{array}$ & $\begin{array}{l}\text { P } \\
\text { Value }\end{array}$ \\
\hline Women & $2.266(.989-5.192)$ & .053 & & $1.016(.388-2.655)$ & .975 \\
\hline Age (Years) & $.985(.955-1.016)$ & .336 & & $.980(.945-1.017)$ & .282 \\
\hline Minority & $.197(.051-.758)$ & .018 & & $.521(.113-2.405)$ & .404 \\
\hline Symptoms of Anxiety & $1.141(1.024-1.271)$ & .017 & & $.964(.864-1.075)$ & .505 \\
\hline Symptoms of Depression & $.842(.760-.932)$ & .001 & & $.986(.893-1.088)$ & .778 \\
\hline History of Shock & $2.156(1.019-4.562)$ & .045 & & $1.881(.761-4.651)$ & .171 \\
\hline $\begin{array}{l}\text { History of Generator } \\
\text { Replacement }\end{array}$ & $.893(.399-2.001)$ & .783 & & $.805(.304-2.131)$ & .662 \\
\hline ICD Knowledge & $.862(.744-.997)$ & .046 & & $.796(.672-.945)$ & .009 \\
\hline Health Literacy & $1.194(1.003-1.421)$ & .046 & & $1.194(1.003-1.421)$ & .046 \\
\hline
\end{tabular}

The model for the generator replacement scenario $\left(\mathrm{x}^{2}[18, \mathrm{~N}=240] 47.571\right), p,<.001$ was statistically significant. 


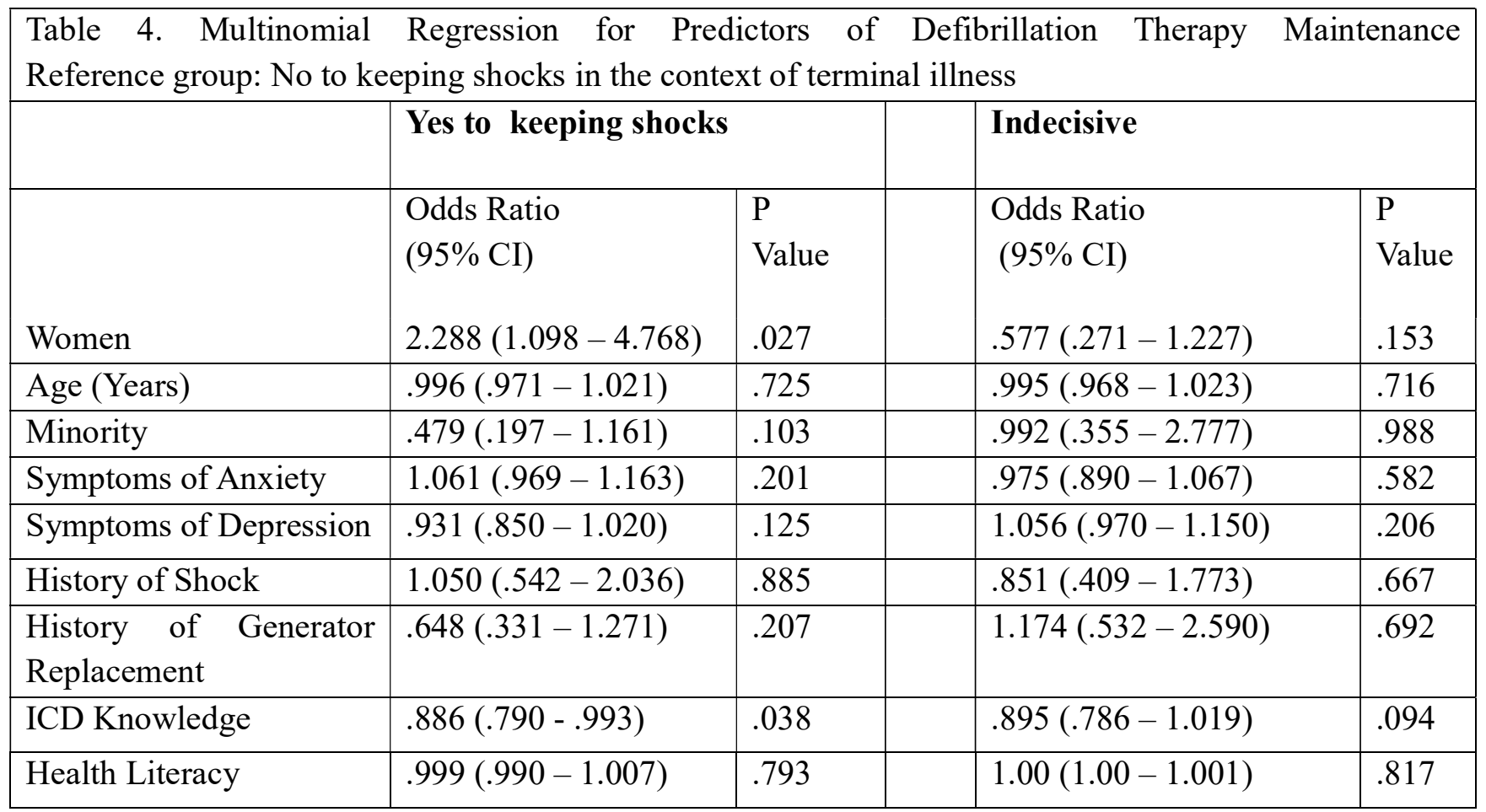

The model for the maintenance of defibrillation therapy scenario $\left.\left(\mathrm{x}^{2}[18, \mathrm{~N}=240] 29.832\right), p, .039\right)$ was statistically significant 